Gut and Liver, Vol. 13, No. 1, January 2019, pp. 1-2

EDITORIAL

\title{
Effects of Abdominal Visceral Fat Change on Regression of Erosive Esophagitis
}

\author{
Ji Yong Ahn \\ Department of Gastroenterology, Asan Medical Center, University of Ulsan College of Medicine, Seoul, Korea
}

See "Effect of Abdominal Visceral Fat Change on the Regression of Erosive Esophagitis: A Prospective Cohort Study" by Su Youn Nam, et al. on page 25, Vol. 13. No. 1, 2019

\begin{abstract}
Previous studies have shown the association between obesity and gastroesophageal reflux disease (GERD), ${ }^{1-3}$ and revealed that abdominal visceral fat can affect a lot on aggravating the GERD based on various theoretical backgrounds. ${ }^{2,45}$ In recent studies, abdominal visceral fat volume measured by cross-sectional computed tomography (CT) was a better predictor of erosive esophagitis than body mass index or waist circumference in both men and women. ${ }^{2,6}$
\end{abstract}

An increase in abdominal adipose tissue can increase intraabdominal pressure, increased gastric pressure, lower esophageal sphincter relaxation, formation of hiatal hernia, and subsequent esophageal acid reflux. ${ }^{7}$ In addition, serum levels of several inflammatory cytokines such as interleukin- 6 and tumor necrosis factor-alpha, which are overexpressed in patients with erosive esophagitis can be elevated by an increase of visceral fat voulume. ${ }^{8}$ Until now, most of studies have been performed to reveal the aggravating factors of esophagitis, therefore, there are less data about the effect of visceral fat change on the regression of erosive esophagitis. This research ${ }^{9}$ maybe the first topic which tried to know about the effects between visceral fat change and the regression of esophagitis.

In this issue of Gut and Liver, Nam et al. ${ }^{9}$ prospectively followed 163 reflux esophagitis patients who had performed esophagogastroduodenoscopy between February 2010 and November 2010. The patients were endoscopically diagnosed as erosive esophagitis at baseline and performed follow-up multidetector CT from May 2010 to August 2013. The longitudinal change of abdominal visceral fat and erosive esophagitis were evaluated in all patients.

Among total enrolled patients, the regression of erosive esophagitis rate was $49.1 \%$ and resulted as a decrease of regression in higher visceral fat group with $3 \mathrm{rd}$ and 4 th quartile at follow-up. Especially, the highest quartile of visceral fat change reduced the probability of the regression of erosive esophagitis compared to the lowest quartile (relative risk, 0.10; 95\% confidential interval, 0.03 to $0.28 ; \mathrm{p}<0.001$ ).

In this study, authors showed that higher visceral fat at follow-up and greater increase of visceral fat during followup period reduced the rate of regression in erosive esophagitis patients regardless of baseline visceral fat volume. Based on this research, there are further considerations. First, using this well designed setting, study to know the change of inflammatory cytokines and lipid profiles which have been revealed as associated factors for visceral fat, ${ }^{8,10}$ according to the change of visceral fat volume, can be considered. This kind of studies can help to solve the problem such as high cost and radiation exposure which should be considered during using CT followup. Second, similar with first opinion, newly designed methods for estimating visceral fat volume instead of CT can be thought. If the results of this study are more clearly demonstrated in additional studies, simpler and safer methods to know the change of visceral fat volume will be need in patients with esophagitis. Third, treatment plan and follow-up methods in patients with erosive esophagitis can be modified that clinicians can emphasize more about weight control and life style change.

This study, which was performed on the foundation of their good previous researches, has important clinical meaning because authors found that the visceral fat change during followup period can affect the regression of erosive esophagitis. Based on these results, further studies to clearly demonstrate the action

Correspondence to: Ji Yong Ahn

Department of Gastroenterology, Asan Digestive Disease Research Institute, Asan Medical Center, University of Ulsan College of Medicine, 88 Olympic-ro 43-gil, Songpa-gu, Seoul 05505, Korea

Tel: +82-2-3010-5667, Fax: +82-2-476-0824, E-mail: ji110@hanmail.net pISSN 1976-2283 eISSN 2005-1212 https://doi.org/10.5009/gnl18299

@ This is an Open Access article distributed under the terms of the Creative Commons Attribution Non-Commercial License (http://creativecommons.org/licenses/by-nc/4.0) which permits unrestricted non-commercial use, distribution, and reproduction in any medium, provided the original work is properly cited. 
mechanism are expected to clinically help reducing esophagitis.

\section{CONFLICTS OF INTEREST}

No potential conflict of interest relevant to this article was reported.

\section{REFERENCES}

1. Nam SY, Choi IJ, Nam BH, Park KW, Kim CG. Obesity and weight gain as risk factors for erosive oesophagitis in men. Aliment Pharmacol Ther 2009;29:1042-1052.

2. Nam SY, Choi IJ, Ryu KH, Park BJ, Kim HB, Nam BH. Abdominal visceral adipose tissue volume is associated with increased risk of erosive esophagitis in men and women. Gastroenterology 2010;139:1902-1911.e2.

3. Corley DA, Kubo A, Zhao W. Abdominal obesity, ethnicity and gastro-oesophageal reflux symptoms. Gut 2007;56:756-762.

4. Chung SJ, Kim D, Park MJ, et al. Metabolic syndrome and visceral obesity as risk factors for reflux oesophagitis: a cross-sectional case-control study of 7078 Koreans undergoing health check-ups.
Gut 2008;57:1360-1365.

5. Ze EY, Kim BJ, Kang H, Kim JG. Abdominal visceral to subcutaneous adipose tissue ratio is associated with increased risk of erosive esophagitis. Dig Dis Sci 2017;62:1265-1271.

6. Lee HL, Eun CS, Lee OY, et al. Association between erosive esophagitis and visceral fat accumulation quantified by abdominal CT scan. J Clin Gastroenterol 2009;43:240-243.

7. Wilson LJ, Ma W, Hirschowitz BI. Association of obesity with hiatal hernia and esophagitis. Am J Gastroenterol 1999;94:28402844.

8. Xu H, Barnes GT, Yang Q, et al. Chronic inflammation in fat plays a crucial role in the development of obesity-related insulin resistance. J Clin Invest 2003;112:1821-1830.

9. Nam SY, Kim YW, Park BJ, Ryu KH, Kim HB. Effect of abdominal visceral fat change on the regression of erosive esophagitis: a prospective cohort study. Gut Liver 2019;13:25-31.

10. Huang CY, Huang HL, Yang KC, et al. Serum triglyceride levels independently contribute to the estimation of visceral fat amount among nondiabetic obese adults. Medicine (Baltimore) 2015;94:e965. 